Check for updates

The BMJ

Cite this as: $B M J 2021 ; 373: n 1552$ http://dx.doi.org/10.1136/bmj.n1552 Published: 16 June 2021

\title{
Covid-19: Delaying end of lockdown will allow more people to be vaccinated, UK government announces
}

\section{Elisabeth Mahase}

The final stage of easing covid-19 restrictions in England, which would have seen all restrictions on social contact removed, has been delayed by four weeks to allow more people to get vaccinated, but researchers warn that deaths could still hit a peak of hundreds a day.

The prime minister, Boris Johnson, said that the delay in easing from 21 June to 19 July could "save many thousands of lives" by allowing millions more people to be vaccinated. He also announced that the target to offer every adult a first vaccine dose by 31 July would be brought forward to 19 July.

Meanwhile, weddings and wakes with more than 30 guests can still go ahead as long as social distancing remains in place, and pilot events will continue, such as for the Euro 2020 football tournament and some theatrical performances. Most restrictions in England have already been lifted, meaning that people can meet indoors, go to restaurants, pubs, and shops, and travel abroad to certain countries.

"As things stand-and on the basis of the evidence I can see right now-I am confident we will not need any more than four weeks and we won't need to go beyond July 19," said Johnson. "It is unmistakably clear the vaccines are working and the sheer scale of the vaccine rollout has made our position incomparably better than in previous waves."

However, modelling carried out for the government by the London School of Hygiene \& Tropical Medicine found that even if the next phase of easing were delayed for five weeks-which would coincide with the school holidays-deaths in England could still reach 500 a day.

\section{Modelling predictions}

The report, which was reviewed by the Scientific Advisory Group for Emergencies (Sage), said that a delay to easing would help to "flatten the summer wave" and reduce the number of deaths (as measured until the end of October 2021) from 49700 to 43500 , with peak deaths reduced from 700 to 500 a day. This modelling is based on a medium immune escape scenario and a $50 \%$ increase in transmissibility of the delta variant, which is now dominant in the UK.

Although the findings appear stark, the researchers noted that the model "is currently overestimating covid-19 deaths." They suggest that this could be due to a number of reasons including that the model is underestimating vaccine efficacy, that it may be producing relatively more cases in older people than have actually been observed, and that the case fatality ratio may have decreased over time because of the frailty effect.
Research by Public Health England has indicated that the delta variant is associated with an estimated $60 \%$ higher risk of household transmission than the alpha variant-which was already much more transmissible than the original version of the virus-and that it could carry a much higher risk of hospital admission. ${ }^{2}$

Looking at vaccine efficacy against the delta variant, reports suggest that two weeks after the second dose the Pfizer-BioNTech vaccine is $88 \%$ effective and the Oxford-AstraZeneca $60 \%$ effective, although both vaccines are only $33 \%$ effective against symptomatic disease three weeks after the first dose.

Meanwhile, the most recent Public Health England analysis reported that two doses of either vaccine were still highly effective against hospital admission: 96\% with Pfizer-BioNTech and $92 \%$ with Oxford-AstraZeneca.

\section{Barnard RC, Davies NG, lit M, Edmunds W]. Interim roadmap assessment: prior to step 4. London School of Hygiene \& Tropical Medicine. 8 Jun 2021 https://assets.publishing.service.gov.uk/government/uploads/system/up- loads/attachment_data/file/993361/S1290_LSHTM_Roadmap_Step_4.pdf. \\ 2 Mahase E. Delta variant: What is happening with transmission, hospital admissions, and restrictions?BM/2021;373:n1513.}

This article is made freely available for use in accordance with BMJ's website terms and conditions for the duration of the covid-19 pandemic or until otherwise determined by BMJ. You may use, download and print the article for any lawful, non-commercial purpose (including text and data mining) provided that all copyright notices and trade marks are retained. 